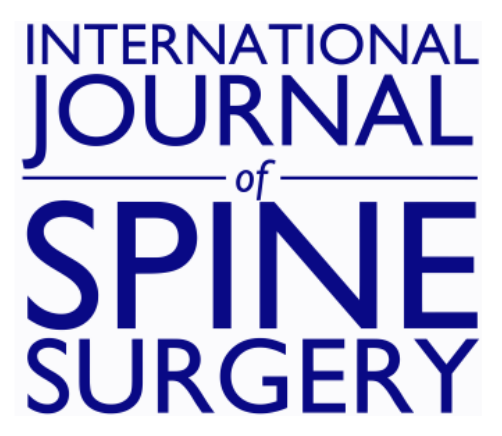

\title{
Adjacent Segment Disease in a Patient With Klippel-Feil Syndrome and Radiculopathy: Surgical Treatment With Two-Level Disc Replacement
}

Alejandro Reyes-Sánchez, Barón Zárate-Kalfópulos and Luis Miguel Rosales-Olivares

Int J Spine Surg 2007, 1 (4) 131-134

doi: https://doi.org/10.1016/SASJ-2007-0114-CR

http://ijssurgery.com/content/1/4/131

This information is current as of April 26, 2023.

Email Alerts Receive free email-alerts when new articles cite this article. Sign up at: http://ijssurgery.com/alerts

The International Journal of Spine Surgery

2397 Waterbury Circle, Suite 1,

Aurora, IL 60504, Phone: +1-630-375-1432 


\title{
Adjacent Segment Disease in a Patient With Klippel-Feil Syndrome and Radiculopathy: Surgical Treatment With Two-Level Disc Replacement
}

\author{
CASE REPORT
}

Alejandro Reyes-Sánchez, MD, Barón Zárate-Kalfópulos, $M D$, and Luis Miguel Rosales-Olivares, $M D$

\begin{abstract}
Klippel-Feil syndrome (KFS) is a complex congenital condition characterized by improper segmentation of cervical motion segments that could contribute to undesirable adjacent segment degeneration. KFS patients have a strong tendency to present with disease in the adjacent segments. When this condition is present, anterior decompression followed by total disc replacement can be performed safely and can lead to good clinical results. This treatment has theoretical advantages compared with anterior decompression and fusion. Comparative studies and long-term follow-up are needed. Complications associated with fusion include loss of a motion segment, disc height loss, subsidence of the graft, progressive degenerative changes at the adjacent level, graft-related complications, and graft-site complications. Such new technologies as motion preservation spine arthroplasty represent attempts to avoid these complications.

Here we present a case report of a 62-year-old female patient with type I congenital fusion at the C5-6 level, with a history of neck pain and right radiculopathy at C5-7. X-rays and MRI show evidence of adjacent segment degeneration at levels above and below congenital fusion. The patient's preoperative visual analog score (VAS) for neck pain was 7 out of a possible 10, her score for right upper extremity pain was 8 out of 10, and her Neck Disability Index (NDI) was 32\%. Surgical treatment consisted of anterior decompression and total disc replacement at both levels. At 1-year follow-up, the patient's VAS for neck pain was 2 out of 10, her VAS score for right upper extremity pain was 1 of 10 , and her NDI was $9 \%$.
\end{abstract}

Key Words Klippel-Feil syndrome, adjacent segment degeneration, cervical total disc replacement, motion preservation. SAS Journal. Autumn 2007; 1:131-134. DOI: SASJ-2007-0114-CR

\section{INTRODUCTION}

Klippel-Feil syndrome (KFS) is a complex, congenital condition originally reported by Maurice Klippel and Andre Feil in 1912. ${ }^{1}$ The classic clinical triad of low posterior hairline, short neck, and limited range of motion is present in between $34 \%$ and $74 \%$ of patients. ${ }^{2,3}$ The "hallmark" of this condition is the improper segmentation of cervical motion segments, discernible as congenitally fused vertebrae with or without clinical manifestations. ${ }^{2}$

Because of the congenital fusion of the cervical motion segments in the KFS patient, abnormal mechanical loading can occur. Additional excessive motion is present because the nonfused cervical segments compensate for the long lever arm and its inability to accommodate load and stress. ${ }^{4}$ Furthermore, such motion at nonfused levels could increase as the number of motion segments decreases. Thus, hypermobility of the nonfused cervical segment adjacent to a fused KFS construct could contribute to undesirable instability and potential injury to neural elements and degenerative changes at the level of a nonfused cervical segment. ${ }^{5,6}$

Usually these degenerative changes occur in patients who are refractory to conservative treatment. These patients have been treated with anterior decompression and fusion of the affected level with good clinical results. ${ }^{7-9}$ The potential complications of spinal fusion in these patients include loss of a motion segment, disc height loss, subsidence of the graft, progressive degenerative changes at adjacent levels, graft-related complications, and graft-site complication. New technologies such as motion preservation spine arthroplasty are attempts to avoid these complications.

We present the case of a woman with adjacent segment disease in the levels above and below congenital fusion in the cervical spine who was treated with total disc replacement.

\section{CASE REPORT}

A 62-year-old female office worker presented with mechanical neck pain radiating into the anterior part of the shoulder along with weakness in the right arm. Her previous treatment included pain medication and physical therapy for 2 years. Her visual analog scores (VAS) were 7 out of a possible 10 for neck pain and 8 out of 10 for upper extremity pain, and her Neck Disability Index (NDI) was 32\%. Her physical examination showed pain and stiffness in the neck; paresis with muscular weakness in L4-5 for wrist flexors and extensor, triceps, and interossei muscles in the right side; and loss of sensibility in 
L2-3 between C5 and T1 in the right upper extremity. The symptoms were aggravated by extension and right side lateral rotation of the head. Anterior and lateral X-rays showed fusion type I of C5-6 levels, loss of cervical lordosis, and decreased height in C4-5 and C6-7 levels (Figure 1). Flexion-extension $\mathrm{X}$-rays showed translational instability in the C4-5 level. MRI findings showed spinal stenosis at C4-5 and C6-7 levels, compression of the dural sac in both levels, and loss of normal disc height and hydration (Figures 2-4).

\section{Figure 1}

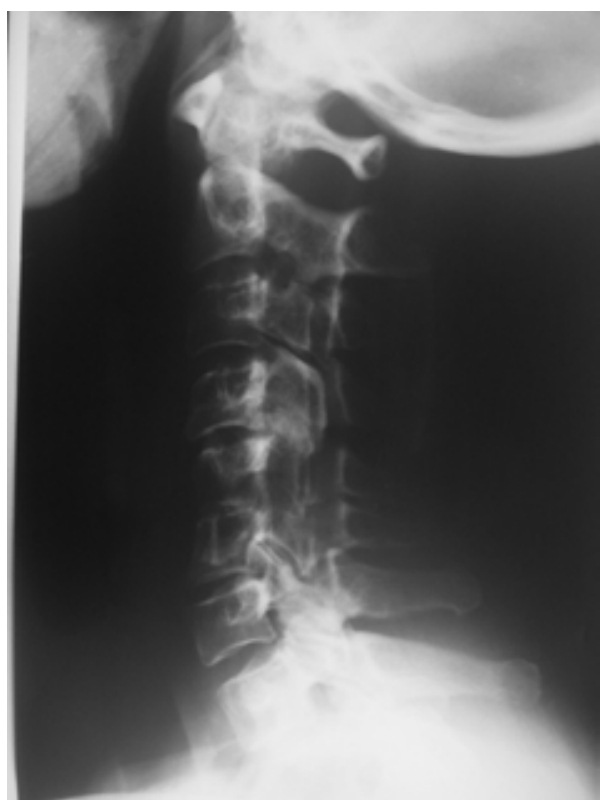

Preoperative lateral view cervical spine shows C5-C6 type I congenital fusion.

We treated the patient at our center using the anterior approach with decompression at C4-5 and C6-7 levels and application of total disc replacement M6 (Spinal Kinetics Inc., Sunnyvale, California, USA) in these two levels (Figure 5).

Postoperative follow-up at 1 year showed improvement in neck and right arm pain. The patient's postoperative VAS at that time was 2 out of 10 for neck pain and 1 out of 10 for upper extremity pain. Her muscle strength also improved. She scored 5 out of a possible 5 in all muscular groups, and her NDI at 1-year follow-up was $9 \%$. The patient was satisfied with these results. One-year postoperative x-rays showed recovery of cervical lordosis and return of normal movement of the motion segments treated with the disc arthroplasty (Figures 6 and 7).

\section{DISCUSSION}

The designation of Klippel-Feil syndrome includes a heterogeneous group of patients unified only by the presence of congenital synostosis of some or all cervical vertebrae. The condition occurs in approximately one in 40,000 to
Figure 2

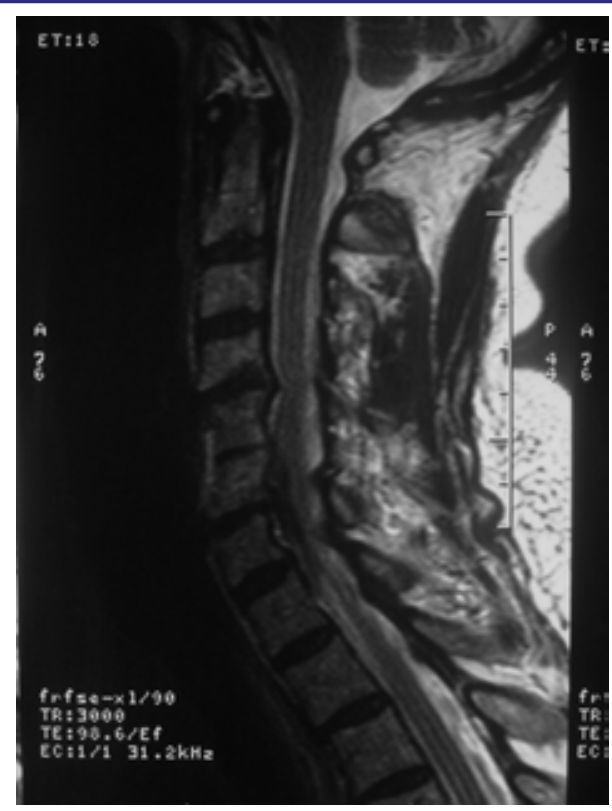

MRI of the cervical spine, sagittal cut in T2. Spinal stenosis at $\mathrm{C} 4-\mathrm{C} 5$ and C6-C7 levels.

\section{Figure 3}

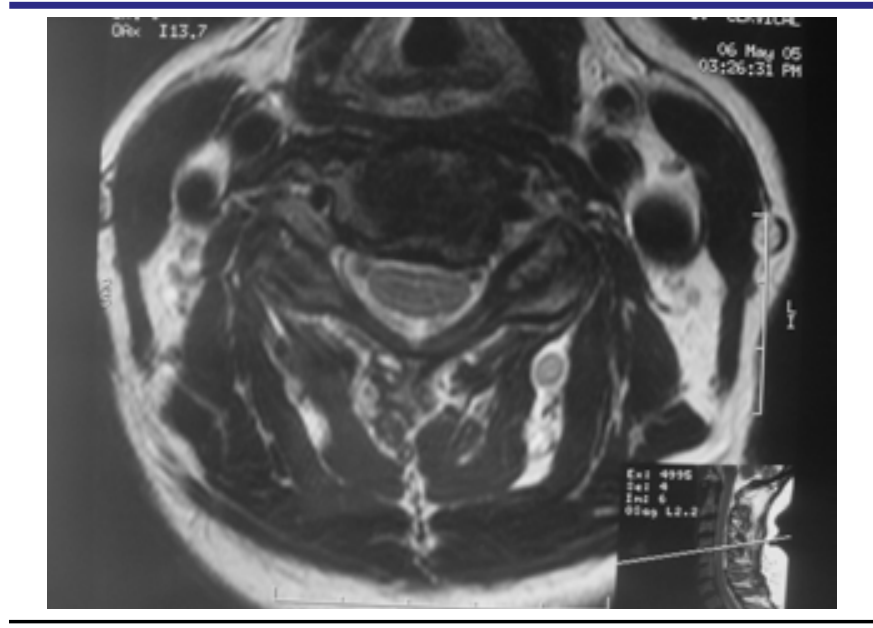

MRI of the cervical spine, axial cut in T2 at C4-C5 level. Spinal stenosis with dural compression.

42,000 births, with a slight female predominance of $3: 2$. The syndrome usually is diagnosed at a later age ( $>40$ years of age) when neurologic, myelopathic, and biomechanical problems are present. Patients with progressive symptomatic segmental instability or neurologic compromise are candidates for surgical stabilization of the abnormal region of the cervical spine. Normally, this is obtained by anterior decompression and cervical fusion with very good documented results. However, there are two special concerns in this type of patient: adjacent segment disease in nonfused levels and loss of cervical motion. Robbins and Hilibrand ${ }^{10,11}$ chronicled 374 patients with a total of 409 anterior cervical arthrodeses. They found symptomatic 
Figure 4

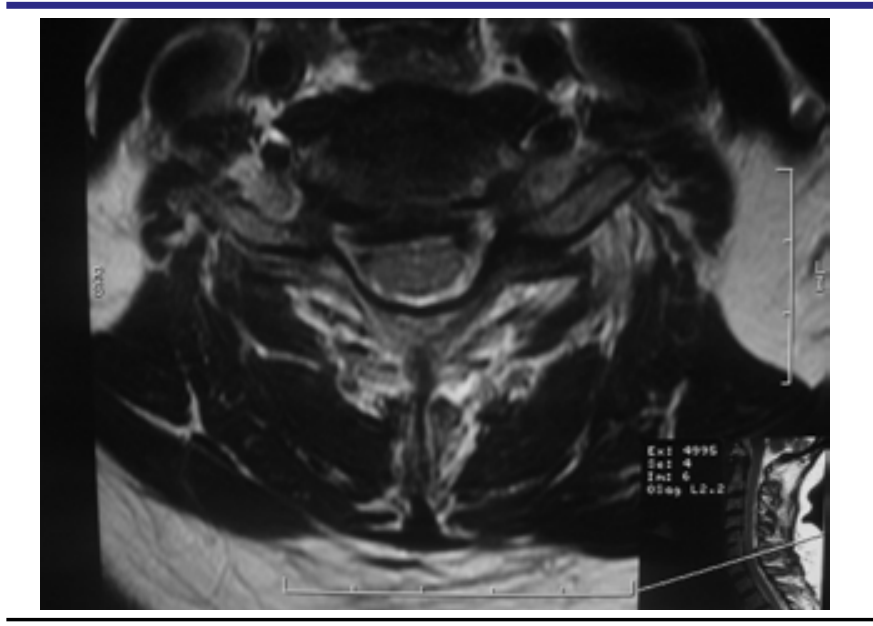

MRI of the cervical spine, axial cut in T2 at C6-C7 level. Spinal stenosis with dural compression.

\section{Figure 5}

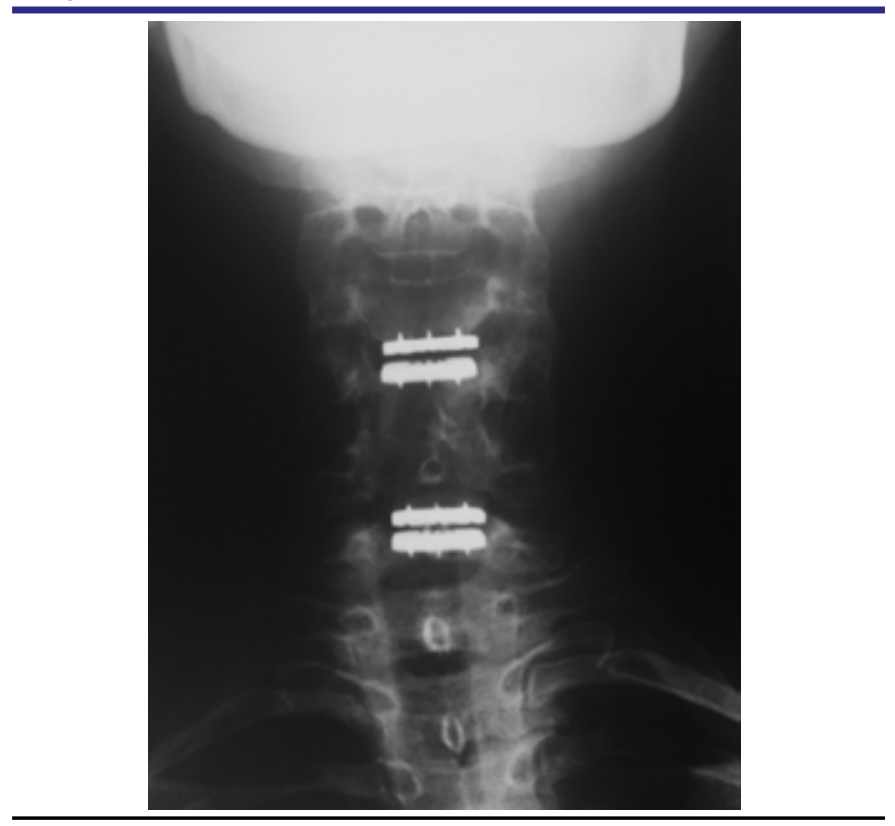

X-ray of the cervical spine, AP view at 1-year follow-up. Shows cervical disc replacement at 2 levels.

adjacent segment disease at a relatively constant incidence of $2.9 \%$ per year $(0.0 \%$ to $4.8 \%) .{ }^{10,11}$ New disease was defined as new onset of myelopathy or radiculopathy significant enough to require surgery. Survivorship analysis projected that $25.6 \%$ of the patients ( $95 \% \mathrm{CI}, 20 \%$ to $32 \%$ ) who had an anterior cervical arthrodesis would have new disease at an adjacent level within 10 years after the operation. The most likely levels to develop adjacent segment disease were C5-C6 and C6-C7. Baba et al. ${ }^{12}$ assessed over 100 patients undergoing anterior cervical fusion for cervical myelopathy with an average of 8.5 years of follow-up. These authors observed that $25 \%$ of these patients subsequently developed new spinal canal stenosis above the previously fused segments. Gore and Sepic ${ }^{13}$ observed new spondylosis in $25 \%$

\section{Figure 6}

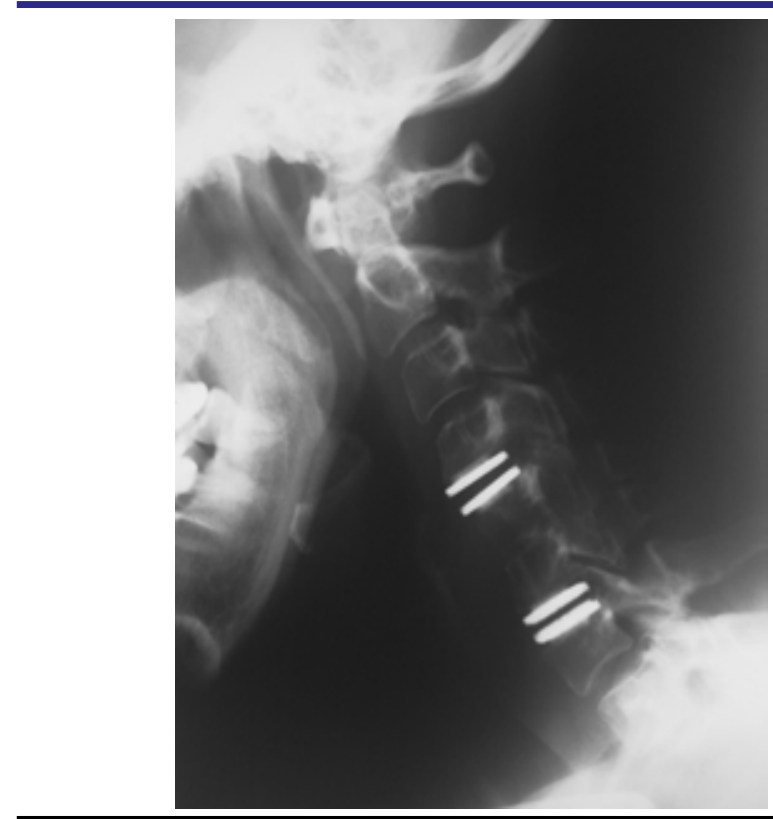

Lateral $x$-ray of the cervical spine in flexion at 1-year follow-up. Shows 2level cervical disc replacement with movement at both levels.

\section{Figure 7}

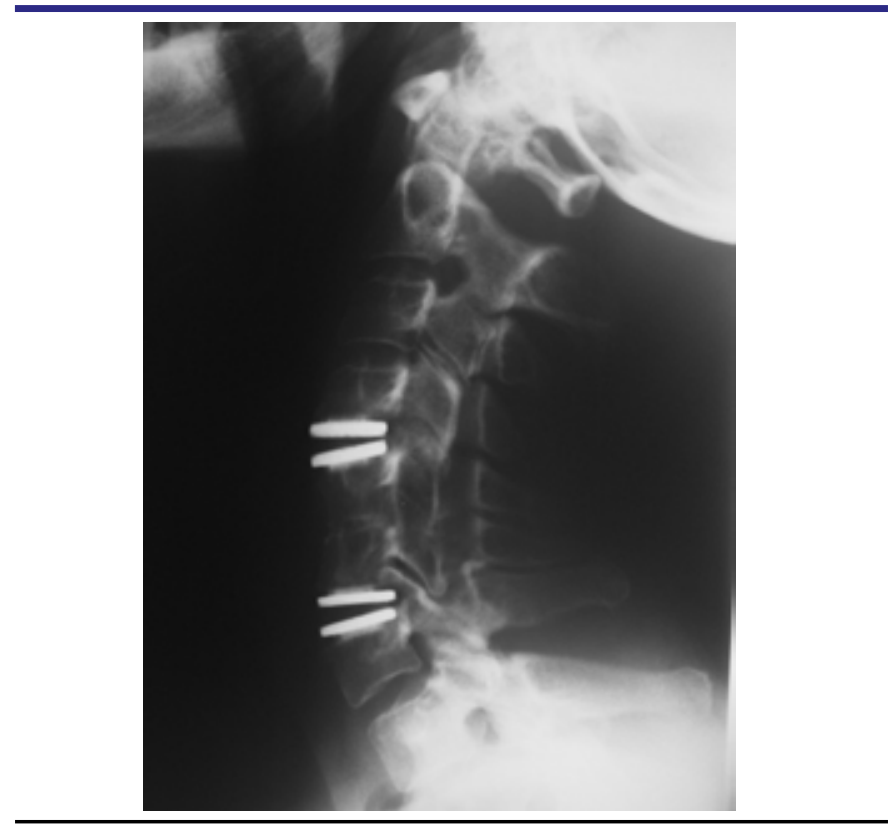

Lateral x-ray of the cervical spine in extension at 1-year follow-up. Shows 2-level cervical disc replacement with movement at both levels.

of 121 patients and progression of preexisting spondylosis in another $25 \%$ of patients who had previously undergone anterior cervical fusion with an average follow-up of 5 years.

Such motion preservation techniques as disc arthroplasty allow restoration of intervertebral disc height and neuroforaminal height and motion after anterior cervical decompression. These 
results seem to offer a better rationale for treatment in these patients. It is still possible that restoration of normal motion to an already diseased spinal segment in the cervical spine with cervical disc replacement will alter the natural rate of adjacent segment degeneration and, in fact, lessen it.

To the best of our knowledge only two studies have reported the use of total disc replacement in patients with KFS. McAfee ${ }^{14}$ reported on 33 patients who underwent a total of 32 porous coated motion (PCM) cervical arthroplasty procedures from C3-4 to C6-7: 15 were in a single level, 7 were in double levels, and 1 was in three levels. Three of these patients had KFS and had been treated with a variety of PCM with supplemental screw fixation in both components. At 9-month follow-up all patients were neurologically intact. A total of $79.9 \%$ of these cases had 15 percentage or more of improvement over preoperative scores on the Oswestry NDI, and $82.6 \%$ had greater than $20 \%$ improvement on VAS. ${ }^{14}$

Pimenta et al. ${ }^{15}$ reported on 53 patients treated with PCM prosthesis. Among these patients, symptoms in two resulted from congenital fusion related to KFS. The average preoperative VAS was 85 points, NDI was $45 \%$, and the average treatment intensity gradient test (TIGT) score was 11.6 points. At 1-year follow-up the mean VAS score was 20 points, the mean NDI was $15 \%$, and the mean TIGT was 3.5 points. According to Odom criteria $57 \%$ reported excellent results. ${ }^{15}$

Each of these studies includes a special report of KFS-related levels treated and the type of congenital fusion performed. We report here on a type $\mathrm{I}^{16}$ congenital fusion of the cervical spine with adjacent segment disease in the levels above and below in a patient who was successfully treated with cervical arthroplasty. One year after surgery, the patient's x-rays showed excellent movement of the segments that were treated. One hopes that this type of treatment will decrease the rate of adjacent segment and improve cervical range of motion and patient satisfaction. We have demonstrated in this case report that this technique is safe and successful in this type of patient. Complications related to the use of cervical disc replacement remain a concern. These complications include heterotopic ossification, persistent pain, prosthetic migration, segmental kyphosis, and device failure. ${ }^{17}$ Long-term follow-up and comparative studies with anterior cervical decompression and fusion are necessary to establish treatment guidelines.

Alejandro Reyes-Sánchez, MD, Barón Zárate-Kalfópulos, MD, and Luis Miguel Rosales-Olivares, MD

From the National Rehabilitation Center Spine Service, Mexico City, Mexico

Address correspondence and reprint requests to Barón Zárate-Kalfópulos, Calzada México Xochimilco \#289, Colonia Arenal de Guadalupe, México Distrito Federal (email: baronzk@hotmail.com)

This paper was submitted on September 5, 2007 and accepted for publication on October 17, 2007.
Alejandro Reyes-Sanchez, MD, is a consultant for Spinal Kinetics (Sunnyvale, California, USA).

\section{REFERENCES}

1. Klippel M, Feil A. Un cas d'abscence des vertebres cervicales. Avec cage thoracicque remontant jusqu'a la base du creane (cage thoracique cervicale). Nouv Iconog Salpetriere. 1912;25:223-250.

2. Hensinger R, Lang J, MacEwen G. Klippel-Feil syndrome: a constellation of associated anomalies. J Bone Joint Surg Am. 1974;56:1246-1253.

3. Pizzutillo P, Woods M, Nicholson L, et al. Risk factors in Klippel-Feil syndrome. Spine. 1994;19:2110-2116.

4. Samartzis D, Libicky J, Herman J, Kalluri P, Francis S. Symptomatic cervical disc herniation in a pediatric Klippel-Feil patient: the risk of neural injury associated with extensive congenitally fused vertebrae and hypermobile segment. Spine. 2006;31:335-338.

5. Guille J, Miller A, Bowen R, Forlin E, Caro P. The natural history of Klippel-Feil syndrome: clinical roentgenographic, and magnetic resonance imaging findings at adulthood. J Pediatr Orthop. 1995;15:617-626.

6. Lee $\mathrm{CK}$, Weiss $\mathrm{AB}$. Isolated congenital cervical block vertebrae below the axis with neurological symptoms. Spine. 1981;6:118-124.

7. Bonola A. Surgical treatment of the Klippel-Feil syndrome. J Bone Joint Surg Br. 1956;2:440-449.

8. Hesinger R. Congenital anomalies of the cervical spine. Clin Orthop. 1991;264:16-38.

9. Thomsen M, Schneider U, Weber M, et al. Scoliosis and congenital anomalies associated with Klippel-Feil syndrome types I-III. Spine. $1997 ; 22: 396-401$.

10. Robbins M, Hilibrand A. Post-arthrodesis adjacent segment degeneration. In Complications of Pediatric and Adult Spinal Surgery. Edited by Vaccaro A, Anderson DG, Crawford A, Benzel E, Regan JM. Philadelphia: Lippincott; 2003.

11. Hilibrand AS, Carlsob GD, Palumbo MA, Jones PK, Bohlman HH: Radiculopathy and myelopathy at segments adjacent to the site of a previous anterior cervical arthrodesis. J Bone Joint Surg Am. 1999;81:519-528.

12. Baba H, Furusawa N, Imura $\mathrm{S}$, et al. Late radiographic findings after anterior cervical fusion for spondylotic myeloradiculopathy. Spine. 1993;18:2167-2173.

13. Gore DR, Sepic SB: Anterior cervical fusion for degenerated or protruded discs: a review of one hundred forty-six patients. Spine. 1984;9:667-671.

14. McAfee P. The indications for lumbar and cervical disc replacement. Spine J. 2004;4:177S-181S.

15. Pimenta L, McAfee P, Capuccino A, Bellera F, Helmut D. Clinical experience with the new artificial cervical PCM (Cervitech) Disc. Spine J. 2004; 4:315S-321S.

16. Gore DR, Sepic SB. Anterior cervical fusion for degenerated or protruded discs: a review of one hundred forty-six patients. Spine. 1984;9:667-671.

17. Pickett GR, Sekhan LH, Sears WR, et al. Complications with cervical arthroplasty. J Neurosurg Spine. 2006;4:98-105. 